7-1985

\title{
Patterns of Homicide in North India: Some Sociological Hypotheses
}

Hans Nagpaul

Cleveland State University, h.nagpaul@csuohio.edu

Follow this and additional works at: https://engagedscholarship.csuohio.edu/clsoc_crim_facpub

Part of the Criminology Commons, and the Other International and Area Studies Commons How does access to this work benefit you? Let us know!

Original Citation

Nagpaul, H. (1985). Patterns of Homicide in North India: Some Sociological Hypotheses. International Journal of Offender Therapy and Comparative Criminology, 29(2), 147-158. doi:10.1177/ $0306624 X 8502900207$

\section{Repository Citation}

Nagpaul, Hans, "Patterns of Homicide in North India: Some Sociological Hypotheses" (1985). Sociology \& Criminology Faculty Publications. 58.

https://engagedscholarship.csuohio.edu/clsoc_crim_facpub/58

This Article is brought to you for free and open access by the Sociology \& Criminology Department at EngagedScholarship@CSU. It has been accepted for inclusion in Sociology \& Criminology Faculty Publications by an authorized administrator of EngagedScholarship@CSU. For more information, please contact library.es@csuohio.edu. 


\title{
PATTERNS OF HOMICIDE IN NORTH INDIA: SOME SOCIOLOGICAL HYPOTHESES
}

\author{
Hans Nagpaul, Cleveland State University
}

This article was originally published in:

Nagpaul, Hans (1985). Patterns of Homicide in North India: Some Sociological Hypotheses.

International Journal of Offender Therapy and Comparative Criminology, 147-158.

Post-print standardized by MSL Academic Endeavors, the imprint of the Michael Schwartz Library at Cleveland State University, 2013

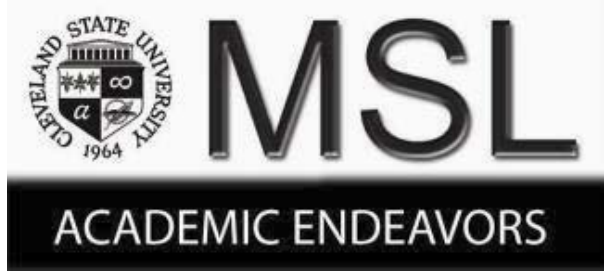




\title{
Patterns of Homicide in North India: Some Sociological Hypotheses
}

\author{
Hans Nagpaul
}

\begin{abstract}
Numerous and varied incidents of homicide are provided. The typical psychiatric and criminological hypotheses appear to be inadequate. Rather a sociological explanation based on rapidly shifting societal major upheavels seem to be a sounder hypothesis.
\end{abstract}

\section{Introduction}

$\mathrm{H}$ omicide is one of the most serious crimes in every society. Societies vary considerably in their homicide rate. In India as well as in America about 20,000 homicides were committed in each country during 1980. The rate varies. For example in India 3.0 homicides per 100,000 occurred, while in America the rate was more than three times this figure. It must be noted that within each society, there are many regional variations.

The present article relates to a geographical and political community in North India, with a population of 1.5 million in 1981. Almost $80 \%$ of the population lives in rural areas and most of the urban population resides in one main city and two medium cities. Forty-two homicides were committed in 1980; six in the main city and the remainder in other parts of the community. Most victims of homicide were known by the offender-in fact in numerous cases the victim was a kinsman. There was a large degree of homogeneity concerning sex, religion and caste of the offenders and the victims. The main motives appear related to disputes concerning agricultural land, residential lots, marital discords, suspicion of husband about chastity of his wife, inadequate dowaries, petty disputes and sudden quarrels.

Notwithstanding the vast cultural differences between Indian and American societies, most of the findings tend to confirm certain well known characteristics believed to surround homicide as a universal phenomenon. What appears unique is the growing number of senseless homicides, especially in urban areas.

In a society which is often characterized as spiritual and non-violently oriented, and where Mahatma Gandhi preached non-violence for almost 
thirty years, it may seem ironic that more than 20,000 homicides (see Appendix-Homicide) are committed every year. These statistics are reported by the Bureau of Police Research and Development, Ministry of Home Affairs, Government of India (1983). The use of violence is a universal phenomenon in all societies. Though it is deplored everywhere, it nevertheless prevails and its rate varies from one society to another. Each society has varying rates within its different regions, cities, urban or rural areas. Apart from national and regional differences, homicides have been found to be related to socio-economic factors, sexual, ethnic and racial characteristics, size of the community, and age structure of the population as reported by the Uniform Crime Reports published annually by the United States Federal Bureau of Investigation (1983). In addition, the main currents of social, economic and political development and the resulting changes affect the magnitude and incidence of homicide in every society. The pace and pattern of rural-urban migration and growth of large cities are yet another group of correlates which are also believed to be responsible for rising rates of homicides world-wide (Sutherland and Cressey, 1978).

\section{Locale and Objectives}

This is essentially an exploratory report to describe the incidence of homicide in a geographical community with definite political boundaries which had a total population of about $1,500,000$ in 1981. The report identifies some of the salient facets of homicides in terms of specific case. Based upon the motives given in the official reports, it further attempts to understand some of the major factors and forces which are believed to have a considerable bearing on the increasing homicidal incidence in contemporary Indian society. Almost 80 percent of this community population is classified as rural where the economy is still predominantly agricultural, though the community is experiencing an impact of industrialization and urbanization during the past several decades. The community is divided into three sub-political units, with a main city of 170,000 population. Among the various groups of population which inhabit the community are those of the Jats, the Brahmans, the Rajputs, the Baniyas and the Harijans in order of the size of their population. These groups are often referred to as castes and subcastes in Indian sociological studies (see Appendix-Caste). The general literacy rate is about 30 percent, higher for the males and in the urban areas, and lower for females and in rural areas. Material possessions such as bicycles, radios etc. have become items of wide ownership, but televisions and automobiles continue to be owned by a very small number of the upper class. A network of public roads and rail transportation is spread throughout the community. Medical and health facilities still remain inadequate in rural areas, though the 
urban areas especially the main city has better facilities, in fact it has a medical college. There appears to be no major religious conflicts in the community. The various population groups, however, are often at odds, and at times show some degree of tension toward each other. This situation does affect the incidence of homicide indirectly at times.

\section{Data Collection}

Basically data have been collected from the official reports of the local police departments and also of the state and national governments. Certain details were obtained from two former judicial officials, two police officers, two faculty members of the local college, two retired civil servants and two local prominent businessmen. Material published in the local English Daily newspaper was utilized. In the course of numerous discussions it became evident that many cases of homicide remain unreported. There was a general concensus that at least 10 percent of the total murders are never reported.

Though the size of population has not changed much during the past decade due to readjustment of the political boundaries of this community, the total number of homicides has nearly doubled. The rural sector continues to account for about 60 percent. In 1970, twenty three homicides were committed but none of them took place in the city. In 1980, six homicides were committed in the city, with 42 occuring in the entire community. In 1975 , the rate per 100,000 population in the city was 1.60 while it was 1.90 for the community as a whole, much below the national level of 3.0. In 1980, the rate in the city more than doubled; it was higher than the rest of the community as well as exceeding the national rate which remained around 3.0.

\section{Patterns of Homicide: Case Examples}

\section{Type I: Homicides Arising from Property Disputes}

In a rural community, removal of cattle fodder by a woman from the agricultural lot belonging to a neighbor led to her murder at the hands of the volatile mortgagor. Although apprehended he terrorized the eye witnesses and fear prevented them from testifying in court. As a result this murderer received acquittal.

In another case, a farmer was murdered by two neighbors because the farmer had tied his two oxen at the site of his neighbors without permission. These two offenders had been drinking prior to the commitment of homicide. The offenders were sentenced to life imprisonment.

In the main city, a young man was killed by two brothers with a carpenter's chisel in a crowded street. The murdered man was having a store constructed on his own lot, and this development would have resulted in the closing down of a window of the home of the killers which 
opened toward the store site. This brutal killing was witnessed by scores of helpless bystanders. None of them would muster enough courage to intervene. The culprits were notorious desperados and bullied citizens of the city. Not a single eyewitness appeared against them in court. They were aquitted.

\section{Type II: Family Violence}

A husband killed his young wife by numerous dagger blows. After disposing of the dead body, he inflicted injuries on his own body to appear as a suicidal attempt. Several neighbors intervened asking why he was attempting to kill himself. He blurted out that he had killed his wife because he found her in bed with another man. He was convicted to life imprisonment. On appeal, the High Court held that the offence was committed under grave and sudden provocation and warranted a more lenient view. The life sentence was accordingly reduced to three years imprisonment. He had already served 3 years and was therefore set free.

A middle aged father in an isolated rural community, molested his young daughter. Eventually other family members became aware. Both father and daughter were murdered while sleeping by his two sons. The sons were arrested but were acquitted because no witness could substantiate the charge of murder.

A chronic drunkard in a small rural community had squandered nearly all his income on alcohol. He was killed by his wife and son for his excessive drinking. The dead body was reported to have been thrown away in a river. For want of reliable eye witnesses, the killers were aquitted.

In another case of a rural community, a sudden domestic quarrel terminated in homicide - the man killed his wife and daughter with a dagger. He was caught by his neighbors who were attracted by the screams. The offender was sentenced to death and the penalty was sustained by the High Court.

In an urban setting, a sudden dispute between two brothers during a card game resulted in injury to one of them. This provoked the injured brother, he brought out a gun from his bedroom and shot his brother to death. A number of neighbors rushed to the scene and sent for the police. The offender was sentenced to life imprisonment. On appeal, he was acquitted as the testimonies of eye witnesses were conflicting.

\section{Type III: Family Violence Concerning Dowry}

In an urban community, a young girl was burnt to death by her husband, his brother and father. Why? She had brought an inadequate dowry. The death was explained by a frequent excuse, namely her clothes had accidently caught on fire, while cooking. The murderers were not 
arrested. This young woman's death was accepted as accidental. Another young woman in the city was strangled to death by her husband for not bringing adequate cash money from her father to clear her husband's debts. The clever husband tried to explain her death by a plea of suicide. The plea failed in the court and the offender was sentenced to life imprisonment. The sentence was upheld on appeal by the High Court. Such gruesome murders of young brides attributable to deficient dowries are reported to have increased considerably in some regions of the country and especially in urban communities where probability of reporting such cases is far higher than in rural communities (see Appendix-Dowry).

\section{Type IV: Situational Homicides}

An altercation over the amount of charges for adjusting two pairs of slacks between a customer and a tailor and his two sons culminated in the killing of the customer-a young man of 22 years old. The testimony of two eye witnesses of the neighborhood who had come to the store resulted in the conviction and sentence of the sons to five years' rigorous imprisonment. The High Court held that the customer had caused considerable provocation and that intention to murder had not been established, hence mild punishment.

Refusal of a pick-pocketer in the main city to offer a drink to his two associates cost his life. One of the companions held him, while the other stabbed him to death. The two culprits were tried for murder. The one who had held the deceased was acquitted. The court decided that there was no evidence to support the contention that this man had shared the common intention of the murderer. The latter was sentenced to five years imprisonment. The court came to the conclusion that death was not proved to have been caused by the injury because the victim had survived for several weeks and no autopsy of the dead body had been performed.

A physical education instructor of a local city college shot one of his students. The student had accused him of favoritism, corruption and mismanagement. The murderous drama was enacted in the presence of a number of students on the college grounds. The murderer was sentenced to ten years of rigorous imprisonment.

\section{Type V: Village Feuds and Political Conflicts}

In a rural community at midnight a group attacked members of another household with long sticks while they were asleep. The police was summoned and three injured persons were taken to the nearby hospital, a distance of ten miles. One person died on the way: another person died in the hospital while the father of the two deceased sons survived. The motive for the homicide was the revenge concerning property disputes. The police failed to apprehend the murderers. 
Recently, a political activist from the lower class was reported to have disappeared from a rural community. This activist had been organizing unskilled workers for almost a year and had often exchanged heated arguments with one of the influential contractors. It was widely believed in the community that the activist had been murdered by a hired killer.

\section{Type VI: Senseless Homicides}

Sheer greed for money prompted two young delinquents to kill a man on the outskirts of the main city. The two delinquents could not be identified though they were seen with the deceased by two cyclists.

In the main city, a theft was committed in a clothing store. The guard was hit on the head with a steel bar by the thief. The guard died in the hospital. The murderer was never apprehended.

Again, in the main city, a young woman was stabbed and her jewelry was taken. She died two weeks later. The offenders were never apprehended.

\section{Type VII: Infanticides}

In 1977, police found a dead body of a small infant wrapped in a blanket near the garbage dump in the main city. The police questioned the neighboring residents but failed to produce any concrete information. For a time there had been rumors about the birth of an illegitimate child. It could not be established whether the infant was born alive or dead. The stigma of illegitimacy continues to be frightening in the community.

\section{Low Rate of Convictions}

Despite the vast heterogeneity of Indian culture and society, a unified judicial system based mainly on the British principles of due process exists. The legal profession has more than two hundred thousand members who are attempting to safeguard the rights of individuals on the one hand and to prosecute the violators on the other hand. The conviction rate for homicides reported during the years 1975, 76' and 77' was about one third success. A number of extraneous factors accounted for the large proportion of acquittals. In many cases, the testimony of eye witnesses were believed to have been purchased by the killers or by the killer's family, as a consequence they did not testify. In a number of cases, consideration of the caste, family ties and close kinship relationships had become so compelling that the witnesses refused to declare the truth. Furthermore, some murderers known for their desperate and brutal activities, forced a number of witnesses to give false evidence. In 1977, this factor emerged clearly when a young man was stabbed to death-he had appeared in the court against one of his assailants several months earlier. Another possible explanation could be related to the Indian criminal procedures which tends to work in favor of the accused who is given the benefit of all reasonable doubts. 


\section{Discussion: The Sociology of Homicides}

The foregoing examples were gathered from 120 homicide cases reported in this community during 1970-80. They represent a considerable diversity - no single theory or theoretical model can fully explain these homicides. At one time, the traditional Persian proverb, "Zir, Zimin, and Zin," i.e. gold, land and women was believed to explain most homicides. This study does confirm the truth of this proverb to a considerable extent. Although motivations of lust, greed, envy, revenge and anger appear responsible for most homicides, there lies buried a complex of other factors and forces for the rising homicidal incidence, not only in Indian society but in many other societies. Unfortunately, as yet no empirical research has been undertaken by Indian scholars into homicide and its various dimensions (Chandra 1967, Clinard 1973, Nayar 1975 and Rao 1967). No systematic study is available concerning the biological and psychological characteristics of offenders and the victims. It must be recognized that some sociological conceptions and theories developed and formulated in the United States and other Western countries provide partial insights for the increasing rate of homicide in both rural and urban communities. In this context, conceptions of: (a) social disorganization; (b) the sub-culture of poverty; (c) the sub-culture of violence; and (d) situational and victim precipitated violence seem to be most relevant for the present discussion (Clinard 1974, Gibbons 1977, Reid 1982 and Shelley 1981).

As a result of industrialization, almost all societies are undergoing considerable socio-cultural change. By now about one fourth of the Indian population is classified as urban; and India has more than two hundred cities with a population over 100,000; India has ten cities of over a million (Census, 1981). For the past three decades, extensive programs of economic and industrial development have been introduced under the various five year plans (see Appendix-Five Year Plan). Both rural and urban communities, and especially the large cities are experiencing rapid changes, traditional values and norms are breaking down. Even the oft-quoted cohesion and solidarity of the joint family system is no longer taken for granted. Together with the programs of economic development, constitutional guarantees to promote social, economic and political equality since the attainment of independence in 1947 have generated unrealistic rising expectations and heightened the prevailing sense of relative deprivation among India's masses. Moreover, aspirations of the common man have increasingly out stripped achievements, and vast gaps between the rich and the poor continue to exist on an extensive scale. These trends seem to have disproportionately affected the lower castes and classes who have traditionally accepted low status, low paying jobs, and poor living conditions. These lower orders are becoming dissatisfied and frustrated 
with their prevailing condition, and a pervasive sense of restlessness is sweeping Indian society. The historical position of subordination ascribed to more than one-fifth of the population, on the one hand, and the perpetual poor living conditions under which they survive, on the other, have always contributed toward the development and learning of such values as toughness, adventurousness, aggressiveness and fatalism, resulting in frequent assaultive and aggressive behavior. The prevalence of unemployment on a gigantic scale in large cities is pushing and reinforcing criminal violence still further.

In every society, there are marked regional differences in rates of criminal violence which usually reflect contrasts in sub-cultural values and norms with regard to the tolerance of overt physical violence. There are many segments of the Indian population which are reported to be more prone to violence in interpersonal relationships than other segments. In the community under study, the Jats were found to be more involved in homicides, especially in rural communities. The Jats resort to physical violence when land disputes arise or when threats are presented to their masculinity and reputation, or when derogatory remarks are uttered, especially relating to women. This subculture of interpersonal violence is also supported by the tradition that these people frequently serve in the military services and keep arms in their homes with or without an official license. Again, a number of homicides grow out of petty arguments and quarrels immediately prior to the violent outbursts. This does support one of the most validated findings in criminological literature that most murders occur over trivial matters, and that killers and victims are often caught up in situations which eventually lead to violent behavior leading to death.

\section{Role of Fire Arms, Alcohol and Films}

Under the British rule of two hundred years the possession of firearms and explosive material was well regulated and a system of licensing was practiced. This continues even today though the availability of guns is easier. Many persons who work in the military services are reported to have placed their arms and ammunitions at the disposal of the other members of the family, and these firearms are used to commit murders. According to the available data, most murders are still committed with indigenous weapons such as choppers, hatchets, axes, spears, chains, knives and bamboo sticks. Though, no concrete evidence is on the record, the connection between alcohol and homicides in almost fifty percent of the cases, appears. At best, it is widely believed that alcohol is one of the likely precipitating factors in violence. No hard-core data is available to establish any direct relationship between violence in films and the rising 
rates of homicide. India happens to have one of the largest movie industries in the world, and every city or town has numerous movie houses. As a matter of fact, movies continue to be one of the major forms of recreation and millions of people watch movies daily. A considerable amount of violence and violent characters are depicted in most movies, and one cannot escape concluding that watching violence is likely to increase aggressive behavior, especially among the young because they learn to accept violence as an approved way of solving problems.

\section{Homicide: A Social Learning Explanation}

Although numerous hypotheses have been developed to explain criminal homicide,the present author believes no single explanation has been found to be adequate. Nevertheless, if the most convincing hypothesis appears to indicate that individuals and groups learn the criminal patterns in the same way as they learn the culturally expected behavior (Clinard 1974, Maccaghy 1980). True, some individuals have biological, genetic, or mental imperfections which may cause their criminal behavior. But in most cases, it is only through the process of social interaction that individuals and groups acquire criminal ways of thinking and acting within a given culture or subculture. If individuals live in a social and physical environment where subcultures of violence take roots either through historical traditions or by adopting lower class lifestyles of roughness, many individuals are more likely to seek these "solutions" to their frustrations, interpersonal conflicts and of oppressive living conditions. Both in rural and urban communities of India, the incidence of all forms of deviant behavior including criminal homicide has been on the increase as the traditional social institutions of socialization and social control are in the process of considerable change, and new values, rules and practices have yet to become an integral part of the dominant Indian culture.

\section{Homicide Control and Prevention}

After decades of research effort and thousands of studies in Western societies, nothing definitive about the causes of homicide has been established. Nor have researchers found any approach which has effectively reduced the incidence of homicide. As a matter of fact the traditional approaches of the punishment, deterrence and rehabilitation of violent criminals are being reexamined in the light of research evidence which indicates that most of the existing programs, including the death penalty have not worked. Although capital punishment is legal in India, very few criminals have been exectuted in recent years. The traditional programs undoubtedly are likely to continue in one form or other. However, in a society where mass unemployment, increasing poverty, unhealthy living conditions, oppressive work settings, and massive inequality are 
widespread, the most important program to control and prevent behavior must begin with their reduction. In a changing society, the need for family life educational programs and job training centers must be recognized. The school must become a focal point to combat antisocial behavior. It is reported that almost 80 percent of the school age children are attending schools at the present time. Hence the school must seize this opportunity to inculcate values about obedience to law, respect for authority and use of legitimate means among children and youth so that they will function as normal adults of tomorrow.

Finally, some beginning should be made to initiate criminological research in order to identify the major social and economic forces which are responsible for the increasing rates of homicide especially in large cities. At the same time, researchers must attempt to study the murderers themselves who are in prisons, in an effort to accumulate indigenous data about the dominant characteristics of their personalities and their motives for homicide. In a developing society like India the role of psychiatry, psychoanalysis and psychology will continue to be marginal for many years. Moreover Western models based upon these disciplines have not proved themselves to be most effective in reducing criminal behavior in general and violent criminal behavior in particular especially in the United States. Hence macro educational programs and services to reduce criminal motivation offer the most promising hope of controlling and preventing the rising rates of homicide in the future. Perhaps the annual homicide rate of one per 100,000 population which prevails in most Western European societies should become the ideal goal to be cherished by every society.

\section{APPENDIX}

1. Caste System. A complex system of Hindu social stratification based upon heredity and ascribed status. Basically five caste groups are identified which are divided into hundreds of subcastes. The Brahmans, the Jats, the Rajputs, the Baniyas and the Harijans constitute both castes and subcastes. Contrary to widespread belief, caste may or may not affect individual occupational mobility, though ritually one caste may be considered superior to another. Generally homicides tend to occur more frequently between intra-caste members than between inter-caste members; however inter-caste homicide does occur in rural communities.

2. Dowry. A practice where the parents of a bride give money, goods, property etc. To the bridegroom and his parents at the time of marriage. Initially it had originated as a practice of giving to daughters a share of the parents estate because they were not legally entitled. In some parts of the country, this practice has come to be manifested in the form of demand made by the bridegroom and his parents and has led to many 
undesirable consequences. In recent years laws have been enacted to reform the practice. Unfortunately the practice continues to exist and financial arrangements are negotiated as a part of the marriage.

3. Five Year Plans. Since 1952, India has launched extensive programs of social and economic development under the various five year plans. The government of India is currently finalizing its seventh plan. These plans formulate policies and actions programs on the one hand and allocate resources on the other for the various sectors of social and economic life.

4. Homicide. Section 299 of the Indian Penal Code states that whoever causes death by doing an act with the intention of causing death or with the intention of causing such bodily injuries as is likely to cause death or with knowledge that he is likely by such act to cause death commits the offence of culpable homicide. Under section 300, Culpable Homicide is murder if the act by which death is caused, is done with the intention of causing death.

\section{REFERENCES}

Bureau of Police Research and Development, Ministry of Home Affairs, Government of India (1983) Crime in India. 1979, New Delhi, India.

Chandra, S. (1967) Sociology of Deviation in India. Bombay, Asia, Allied Publishers.

Clinard, M. (1974) Sociology of Deviant Behavior. New York, N.Y., Holt.

Clinard, M., and Abbott, D. (1973) Crime in Developing Societies. New York, N.Y., Wiley.

Federal Bureau of Investigation, United States Department of Justice (1984) Crime in the United States, Uniform Crime Reports. Washington, D.C.

Gibbons, D. (1977) Society, Crime and Criminal Careers. Englewood, N.J., Prentice Hall.

Maccaghy, C. (1980) Crime in American Society. New York, N.Y., Macmillan.

Nayar, B. (1975) Violence and Crime in India. New Delhi, India, Macmillan.

Registrar General Of Census, Government of India (1981) Census of India. New Delhi, India.

Reid, S. (1982) Crime and Criminology. New York, N.Y., Holt.

Rao, V. (1967) Facets of Crime in India. Bombay, Asia.

Shelly, L. (1981) Crime and Modernization, the Impact of Industrialization and Urbanization on Crime.

Shelly, L. (1981) Readings in Comparative Criminology. Carbondale, IL, Southern Illinois University Press.

Sutherland, E., and Cressey, D. (1978) Criminology. Philadelphia, PA, Lippincott. 


\section{PATTERNS OF HOMICIDE IN NORTH INDIA}

158

Hans Nagpaul, Ph.D., Associate Professor

Department of Sociology

Cleveland State University

Cleveland, Ohio 44115

U.S.A. 